\title{
Persistence of ductus arteriosus with left to right shunt in the older patient
}

\author{
R M MARQUIS, H C MILLER, R J M McCORMACK, M B MATTHEWS, A H KITCHIN \\ From the Departments of Cardiology and Cardio-Thoracic Surgery, Royal Infirmary, the Department of Cardiology, \\ Western General Hospital, and the Department of Cardio-Thoracic Surgery, City Hospital, Edinburgh
}

SUMMARY Eight hundred and four patients with persistence of the ductus arteriosus were seen in Edinburgh between 1940 and 1979. Thirty-seven of them reached the age of 50 years, and in 32 the shunt was exclusively from left to right. Fifteen of the 32 were subsequently treated surgically.

None of the 32 was lost to follow-up. Duration of clinical observation averaged 17 years and extended to over 30 years in eight patients. Their features have been correlated with those from reports of 48 comparable patients in an attempt to clarify the management of the persistent ductus in the older patient. Impairment of left ventricular function is shown as the major risk, even when the ductus is small. Bacterial endarteritis is infrequent.

Surgical treatment carries greater risk than in childhood and early adult life but usually reduces heart size and restores exercise tolerance. Left ventricular dysfunction, however, occasionally vitiates the benefits; symptoms are then incompletely relieved and death from heart failure may occur months or years after operation. Experience in older patients thus emphasises the value of elective operation in childhood, however well the child, however trivial the shunt.

It is concluded that in older patients, the presence or the development of symptoms or cardiac enlargement are almost always indications for surgical treatment. As age increases, especially by the eighth decade, medical treatment may be preferable. Continued follow-up of symptomless patients without cardiomegaly is important because increase in heart size usually precedes further deterioration which can then be prevented by timely surgical treatment.

Most patients with persistence of the ductus arteriosus die before 50 years of age ${ }^{1-3}$ unless treated surgically..$^{45}$ Occasional patients, however, survive with little disability and a few live a normal life span. ${ }^{6-9}$ In the majority of adults, exercise tolerance is liable to deteriorate rapidly ${ }^{10}$ and in them surgical treatment has been of great benefit, even at over 65 years of age. ${ }^{10-12}$ Available information, however, has been based on single case reports with little long term follow-up.

The Edinburgh experience of the persistent ductus since 1940 , with and without surgical treatment, has therefore been analysed and correlated with earlier reports in an attempt to amplify knowledge of the clinical course and improve the management of these older patients.
Patients and methods-Edinburgh experience 1940 to 1979

The 40 years, 1940 to 1979 , have been selected in order to encompass periods before and after 1961 when the first older patient with a persistent ductus was treated surgically in Edinburgh. During this time 37 patients (among a total of 804 with persistence of the ductus) had reached 50 years of age before death, surgical treatment, or their last medical assessment. Twentynine were women and eight were men. In five patients, severe pulmonary hypertension was associated with a right to left shunt. The progress of the 32 patients, in whom the shunt was exclusively from left to right, is the subject of the present study (Table). One of them (case 17) had recanalised after earlier ligation during bacterial endarteritis when 27 years old. Fifteen of them were subsequently treated surgically by division 
of the ductus and suture of aorta and pulmonary artery.

In Edinburgh the first ligation was performed in $1940^{13}$ and some of the older patients have been under observation for prolonged periods. The progress of 31 of the 32 patients was known beyond 50 years of age from between four and 30 years, an average of 11 years, a total of 347 patient years without surgical treatment. The earliest physical signs had been noted at 19 years of age (case 6 ) and in 22 patients they had been observed repeatedly for more than a year, the longest for 39 years (case 19), an average of 17 years, a total of 382 patient years before operation or last medical follow-up. Fourteen of the 15 operated upon between 50 and 64 years of age survived and have been followed after operation for from eight months to 18 years, an average of 11 years, a total of 159 patient years. Eleven of the 32 patients have died. Ten have been followed to the eighth decade, three of them without surgical occlusion of the ductus.

\section{DIAGNOSIS}

All 32 patients had a characteristic continuous murmur; in all of them the clinical diagnosis was supported by electrocardiographic and radiological findings; it was confirmed by special investigation in 20 , by surgical treatment in 15 , and by necropsy in four (Table).

\section{SYMPTOMS}

None of the patients could recollect disability in early adult life; many had undergone routine medical examination during intercurrent illness, during pregnancy, or before abdominal or other surgery; the heart disease had usually escaped detection, had been misdiagnosed, or had been dismissed as trivial. Some may have been unaware of diminished exercise tolerance, as postulated by Cassels, ${ }^{14}$ but many had been leading full and active lives. Twenty-eight patients denied disability at 50 years, 12 did not develop symptoms until over 60 years, and three reached 70 years before their exercise tolerance became impaired. Nevertheless, 19 patients developed left ventricular failure (with or without secondary right ventricular failure): 10 between 50 and 59 years (cases 8, 14, 17, 18, 19, 20, 23, 24,27 , and 29), six between 60 and 69 years (cases 7,9 , $15,21,28$, and 31 ), and two shortly after reaching 70 years of age (cases 5 and 11); only one patient had first developed left ventricular failure at under 50 years of age and that was during her third and last pregnancy (case 32). It is probable that a mongol with known heart disease had been disabled to some extent since birth; this had been recognised on admission to a mental hospital in childhood but a cardiac opinion had not been sought until she had developed heart failure when 58 years of age (case 14); another woman with associated but initially mild aortic valve disease had first noticed some exertional dyspnoea at 42 years of age (case 20) but most patients had remained symptomless until shortly before the onset of left ventricular failure. Five patients, who had not been treated surgically, died in congestive heart failure between the ages of 58 and 75 years (cases $7,9,11,14$, and 15). One of those who went into congestive heart failure at 59 years of age had declined earlier surgical treatment, had borne 12 children without cardiac distress, and had been in full time clerical work until the onset of failure (case 27). Three patients developed angina of effort between 50 and 59 years (case 26, 29, and 30), one of whom also had heart failure. One patient without previous disability developed bacterial endarteritis at 54 years of age (case 25). One patient, who had been liable to palpitation and syncope since the age of 45 years, died suddenly at 55 years of age (case 8), and another, who had previously been very active, experienced three episodes of exertional syncope before presenting with acute left ventricular failure when 61 years old (case 21).

The symptoms of most of these older patients with a persistent ductus were thus more severe and occurred earlier than could be accepted as a result of normal ageing.

\section{SIGNS AND RESULTS OF INVESTIGATION}

Reliable records of the physical signs during childhood were not available for any of these older patients. In adult life the signs were known in only five patients at under 30 years of age (cases 1,6,17, 19, and 27), and in another seven at under 50 years of age (cases 2, 8, 13, $20,22,23$, and 30). All had the characteristic continuous murmur though it had sometimes escaped detection initially because of associated aortic valve disease (case 20), or until heart failure had been brought under control (cases 7, 15, and 32). Normal rhythm was usual until the development of heart failure. Atrial fibrillation was present in 11 (cases 5,7 , $9,11,14,15,17,21,27,28$, and 31 ) of the 13 patients in whom left ventricular failure had progressed to failure of the right heart. Its onset was known to have preceded the left ventricular failure in one patient (case 17) and to have developed before progression from left ventricular failure in two others (cases 21 and 28). It is not known in how many of the other patients the onset of atrial fibrillation antedated the right ventricular failure. The pulse pressure exceeded $40 \mathrm{mmHg}$ in every patient; the systolic pressure was raised more often than the diastolic pressure was low and tended to rise progressively with age (Table).

The heart was not enlarged (cardiothoracic ratio of 0.50 or less) in eight of the 12 patients examined at under 50 years of age (cases 1, 2, 12, 13, 19, 22, 23, and 30 ), or in six patients first diagnosed at 50 or more years of age (cases 3, 4, 12,16, 25, and 26). Whether the 

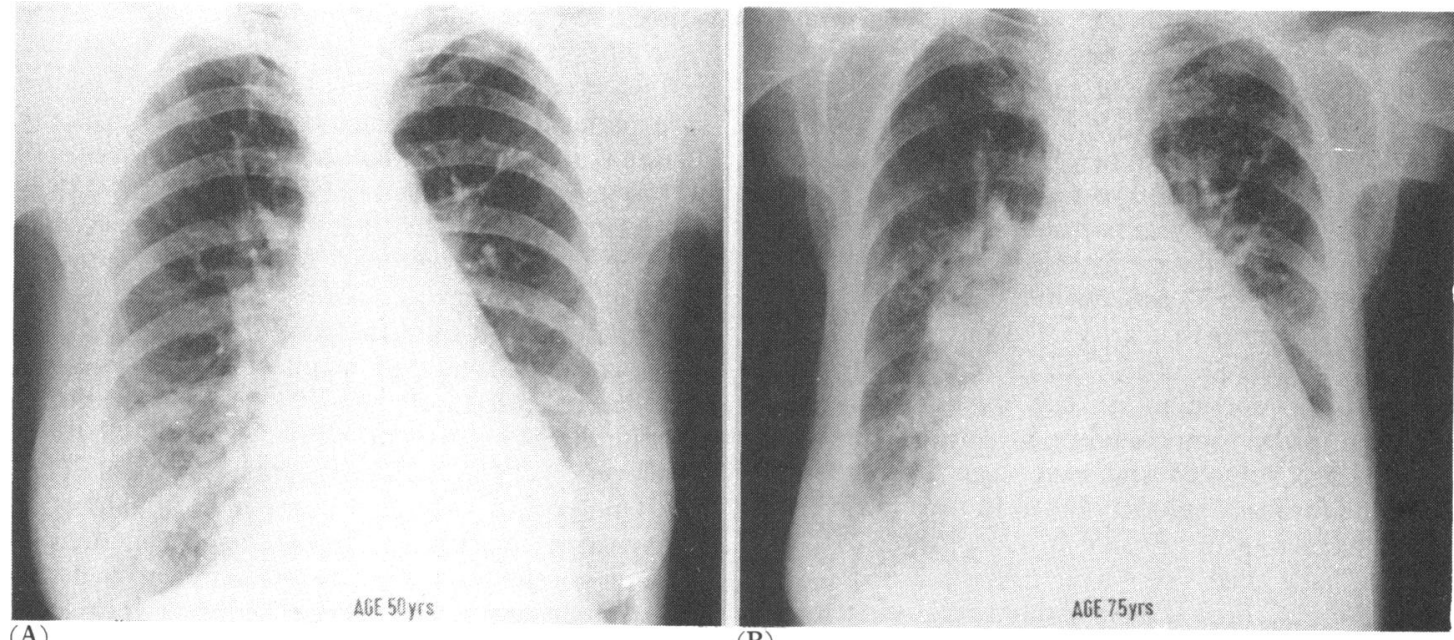

(B)

Fig. 1 Radiological appearances $(A)$ at 50 years of age and $(B)$ at 75 years of age in a woman with a large ductus at necropsy who had denied disability and remained in active employment until 70 years of age (case 11 ).

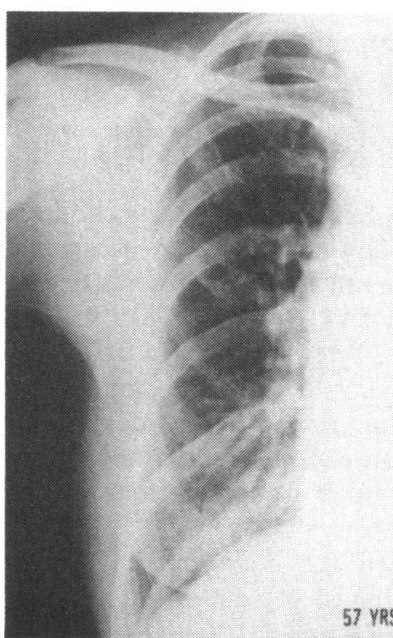

(A)

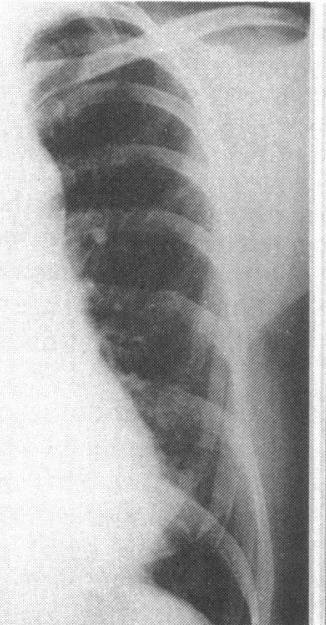

(B)

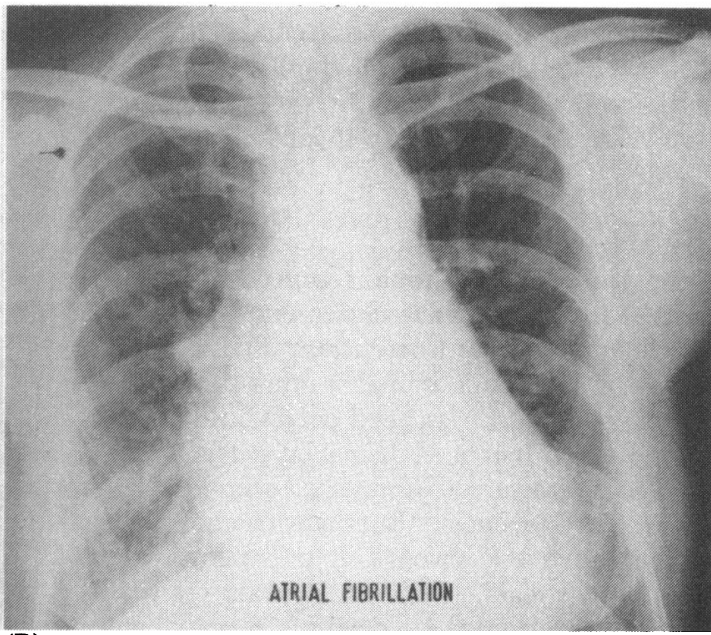

(B)

Radiological appearances at 57 years of age $(A)$ before and $(B)$ after the onset of atrial fibrillation in a woman whose heart had remained unenlarged since recanalisation of a ductus ligated during bacterial endarteritis 30 years previously (case 17).

heart was initially large or small, subsequent increase in heart size was usual as age advanced (Fig. 1 and 2). Only four of the 16 patients of over 60 and only one of the six over 65 still had normal sized hearts. Left ventricular hypertrophy ${ }^{15}$ was present in only two of the 12 patients examined electrocardiographically at under 50 years of age but sometimes developed before cardiac enlargement. It increased with inversion of the left ventricular $\mathrm{T}$ waves as age advanced (Table; see Fig. 9); in all but two patients (cases 5 and 32) the $T$ wave inversion preceded the administration of digoxin. Left bundle-branch block occurred in three patients (cases 9, 15, and 21), and right bundle-branch block was present in one patient (case 31). Electrocardiographic evidence of left ventricular hypertrophy was absent in only one of the 19 patients with heart failure (case 29).

Twenty of the 32 patients were investigated by cardiac catheterisation but serial studies were not performed. Most had been investigated shortly after the clinical diagnosis had been made (cases 4, 5, 12, 13, 14, $18,21,24,26$, and 31 ) but some not until shortly before surgical treatment (cases 19, 20, 22, 23, 27, 28, and 30). In three patients operation was decided against or declined at the time of their investigation (case 10 at 67 years; case 17 at 57 years; case 32 at 54 years). In each 


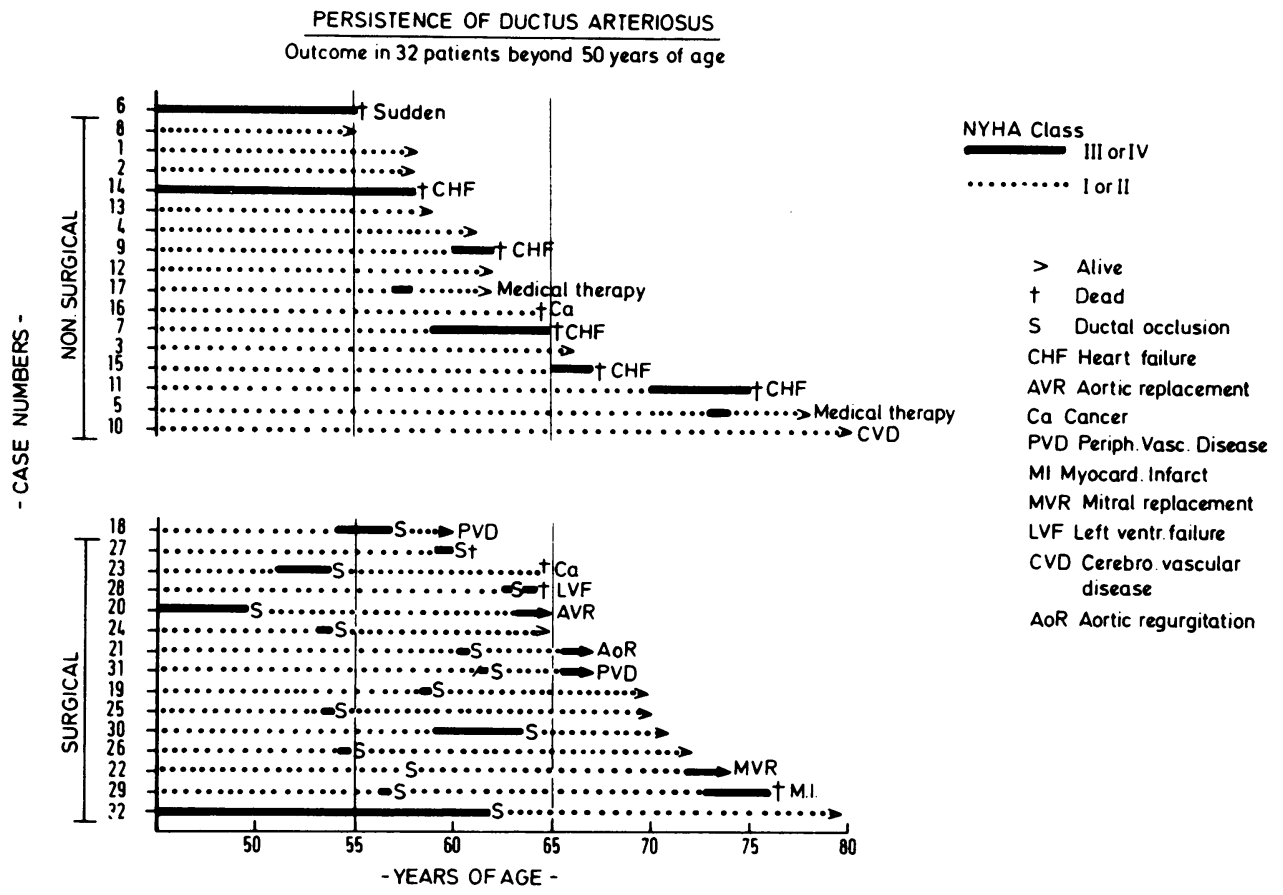

Fig. 3 The outcome beyond 50 years of age of the 32 Edinburgh patients. Non-surgical patients were younger and became disabled later than patients in the surgical group. By 65 years of age, however, nine postoperative patients were symptomless compared with four in the non-surgical group.

case heart failure or other complication had been brought under medical control before the cardiac catheterisation. The ratio of pulmonary to systemic blood flow was seldom greater than 2:1 and was often less (Table); in two patients intracardiac oximetry did not disclose a shunt and confirmation of the clinical diagnosis required aortography (cases 10 and 13). The pulmonary arterial pressure at rest was $30 / 16 \mathrm{mmHg}$ or less in eight patients (cases 10, 12, 13, 17, 19, 20, 26, and 32).

Right ventricular failure had developed in 13 patients (cases 5, 7, 9, 11, 14, 15, 17, 21, 23, 27, 28, 29, and 31 ) but had always been secondary to initial failure of the left ventricle. Eight of these patients had been investigated by cardiac catheterisation: in three of them the pulmonary arterial pressure had measured between $21 / 12$ and $38 / 25 \mathrm{mmHg}$ (cases 5, 17, and 23), in four the pressure had been between 55/25 and 57/27 $\mathrm{mmHg}$ (cases 15, 21, 28, and 31), and the one patient in whom the pressure had reached $105 / 35 \mathrm{mmHg}$ had an aortic pressure of $150 / 50 \mathrm{mmHg}$. The relatively high pulmonary arterial pressures in these last five patients was associated with left to right shunts of 2:1 or more and a rise in the pulmonary wedge pressures. They all had typical continuous murmurs.

The course of the 32 patients and their outcome, with and without surgical treatment, are illustrated diagrammatically in Fig. 3.

\section{SURGICAL TREATMENT AND FOLLOW-UP}

The ductus in 15 patients was divided surgically (cases 18 to 32), in one because of increasing heart size (case 22) and in 14 because of severe symptoms. Heart failure had always responded to initial medical treatment, sometimes with decrease in heart size; bacterial endarteritis in one patient (case 25) had responded to antibiotics before operation was undertaken. Hardening with varying degrees of calcification of the ductus and adjacent great vessels tended to make dissection difficult. As this increased the risk of haemorrhage prior preparation of aorta and pulmonary artery for emergency clamping had usually been completed. Haemorrhage from the back of the ductus or pulmonary artery complicated dissection in two patients with a small ductus (cases 21 and 26) and in one in whom the ductus was large (case 27). Application of a Potts vascular clamp lacerated a partially calcified ductus in another patient (case 25) and the risk of haemorrhage may also have been reduced by induction of hypotension in a patient with heavy calcification (case 28). The division of the ductus was successful in all patients. One patient died from a 


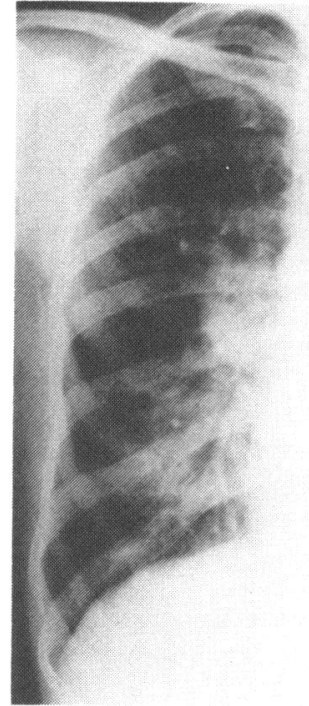

(A)

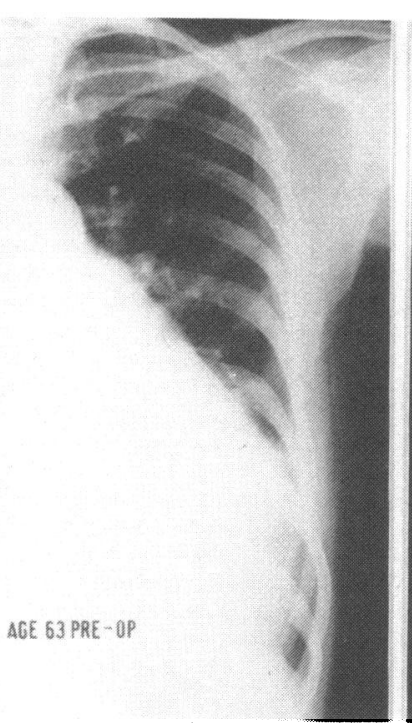

(B)

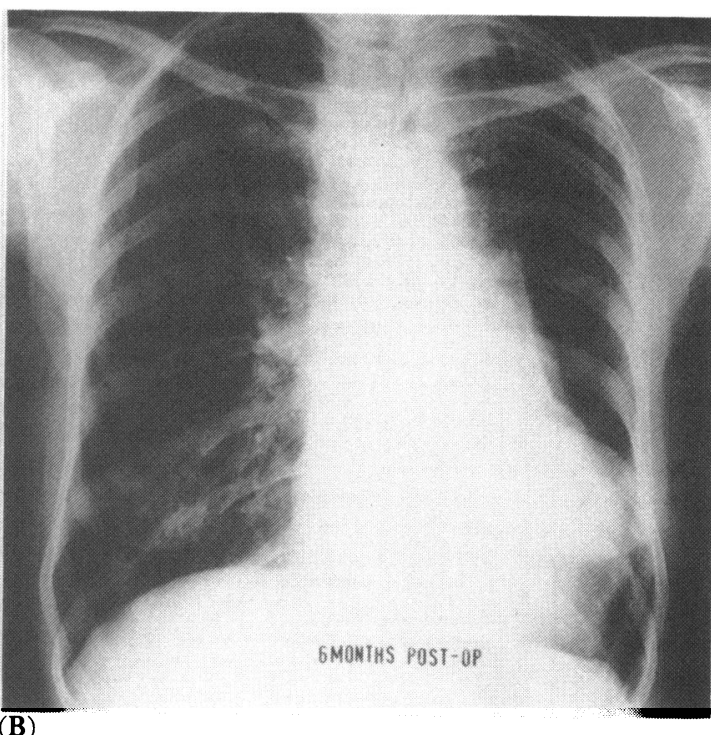

SMONIUS POST - OP

Fig. 4 Radiological appearances at 63 years of age $(A)$ before and $(B)$ six months after division of a 9 mm ductus. Atrial fibrillation had been returned to normal rhythm by direct current cardioversion after operation but exertional dyspnoea persisted and death in acute pulmonary oedema occurred eight months later (case 28).

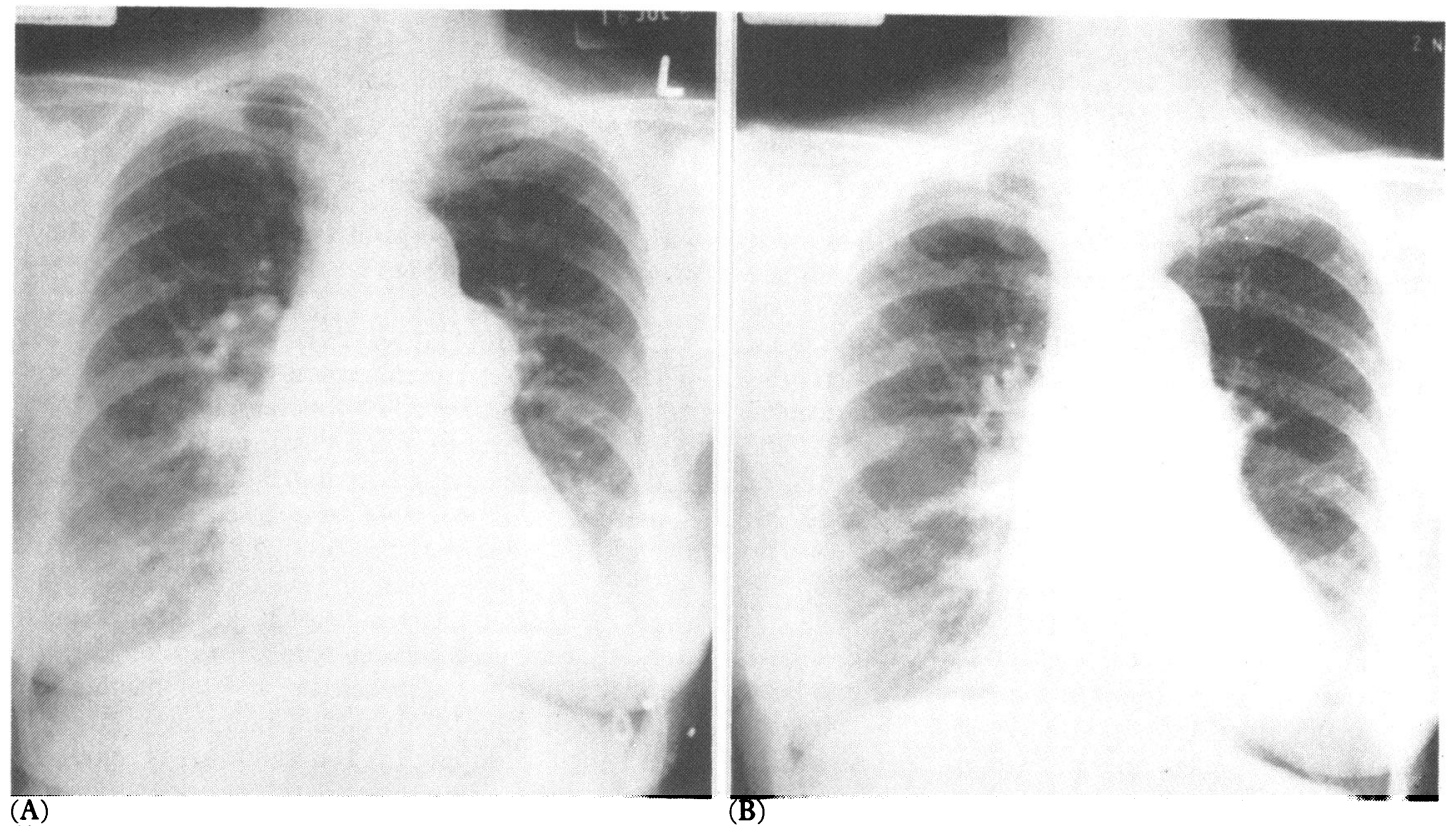

(A)

(B) maintained on digoxin until heart failure became intractable. Well-being was restored by operation and she remains well at 80 years of age (case 32).

cerebral infarct sustained at operation (case 27); her postoperative cardiac state had been satisfactory, her blood pressure was $130 / 60 \mathrm{mmHg}$, and post mortem the hypertrophied left ventricular myocardium had only mild patchy interstitial fibröis. A second patient, whose preoperative blood pressure had been 210/66 $\mathrm{mmHg}$, required antihypertensive treatment in the immediate postoperative period, and mild hypertension 
(BP $200 / 100 \mathrm{mmHg}$ ) persisted subsequently. She remained severely disabled after operation, in spite of considerable decrease in heart size (Fig. 4), and died in acute left ventricular failure eight months after operation. Necropsy showed left ventricular fibrosis but no coronary artery disease or myocardial infarction (case 28). In the 13 other patients, the operative result was good. The external diameter of the ductus had been less than $10 \mathrm{~mm}$ in five patients who had had severe heart failure with gross cardiomegaly (cases 21, 24, 28, 29, and 31).

Decrease in heart size after operation was usual and was often considerable (Fig. 5). Nine patients with exertional dyspnoea, eight of whom had been in frank heart failure, were restored to a normal exercise tolerance (cases 18, 19, 20, 21, 23, 24, 29, 31, and 32); the angina in three patients was relieved (cases 26, 29, and 30); and the patient who had had bacterial endarteritis at 54 years was symptomless and had no cardiac enlargement at 70 years of age (case 25). Of the five patients with atrial fibrillation at the time of ductal division, two reverted spontaneously to normal rhythm several years after operation (cases 30 and 31), and one responded to direct current cardioversion (case 28). Atrial fibrillation persists in one patient with aortic valve disease (case 21). The patient who died from cerebral infarction sustained at operation was also among those with preoperative atrial fibrillation (case 27). One patient, who had been in heart failure with a small ductus, developed atrial fibrillation temporarily during the immediate postoperative period (case 23). Three others developed atrial fibrillation years later, two in association with valve disease (cases 20 and 22), one in relation to ischaemic heart disease (case 29).

Unfortunately, other diseases of increasing age have reduced the duration of improvement (Fig. 3). Deaths 10 and 18 years after operation resulted, respectively, from cancer and myocardial infarction (cases 23 and 29). Severe valve disease developed in three patients; in one with aortic regurgitation, gross left ventricular dysfunction eight years after division of the ductus rendered him unsuitable for aortic valve replacement (case 21) but calcific aortic stenosis (case 20) and prolapse of the mitral valve (case 22) responded well to valve replacement 15 and 14 years, respectively, after ductal division. Peripheral vascular disease crippled two patients three and six years after surgical treatment (cases 18 and 30) and one patient developed bronchial carcinoma, mitral valve prolapse, and renal carcinoma between 10 and 12 years later (case 19). Five patients (cases 24, 25, 26, 31, and 32), now between 65 and 80 years of age and from five to 18 years (average 13 years) after operation, are leading normal lives without significant cardiac enlargement (Fig. 5).

\section{LONG TERM CARE WITHOUT SURGICAL TREATMENT}

Eleven patients have remained relatively well without surgical treatment (Fig. 3) but one of them, aged 80 years, has gross cardiomegaly and is house-bound as a result of cerebrovascular disease (case 10); two with atrial fibrillation and cardiomegaly have been in heart failure but have responded well to medical treatment (cases 5 and 17). One patient died from cancer at 64
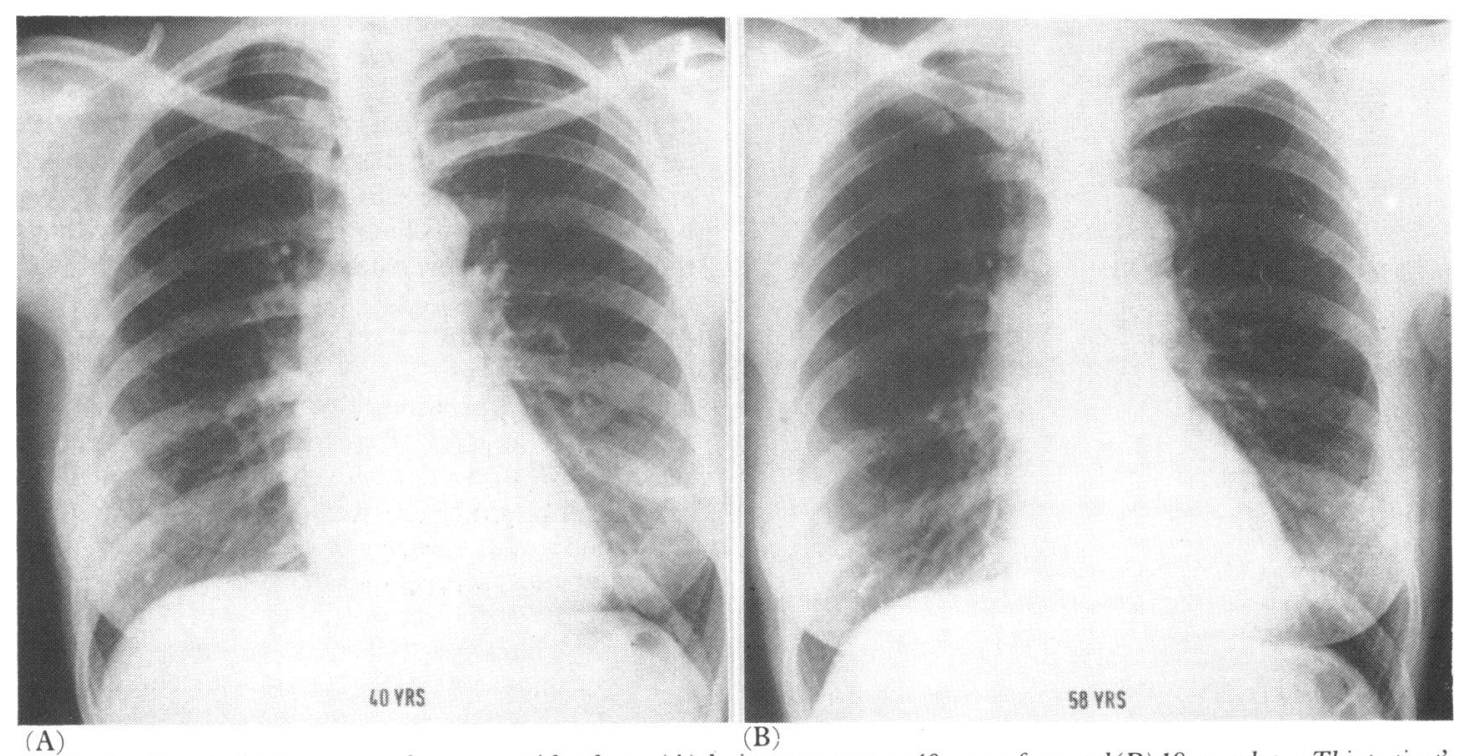

Fig. 6 Radiological appearances of a woman with a ductus $(A)$ during pregnancy at 40 years of age and $(B) 18$ years later. This patient's second pregnancy at 45 years was also uncomplicated and she remains symptomless at 59 years (case 13). 
years of age; she had slight cardiomegaly but no cardiac symptoms (case 16). The seven other patients deny disability, although one has electrocardiographic evidence of left ventricular hypertrophy and slight cardiac enlargement (case 12) and one has advanced left ventricular hypertrophy and gross cardiac enlargement (case 6). Five have neither left ventricular hypertrophy nor cardiac enlargement (cases 1, 2, 3, 4, and 13).

Surgical treatment had been considered for each of these 11 patients. It was declined by two, one more than 30 years ago (case 6) and the other after the development of atrial fibrillation (case 17). Operation was not advised in one patient with increasing cardiac enlargement at 67 years of age because her left to right shunt was too small to be detected by cardiac catheterisation (case 10) and in another, with advanced left ventricular hypertrophy and gross cardiomegaly, because of her age and excellent response to medical

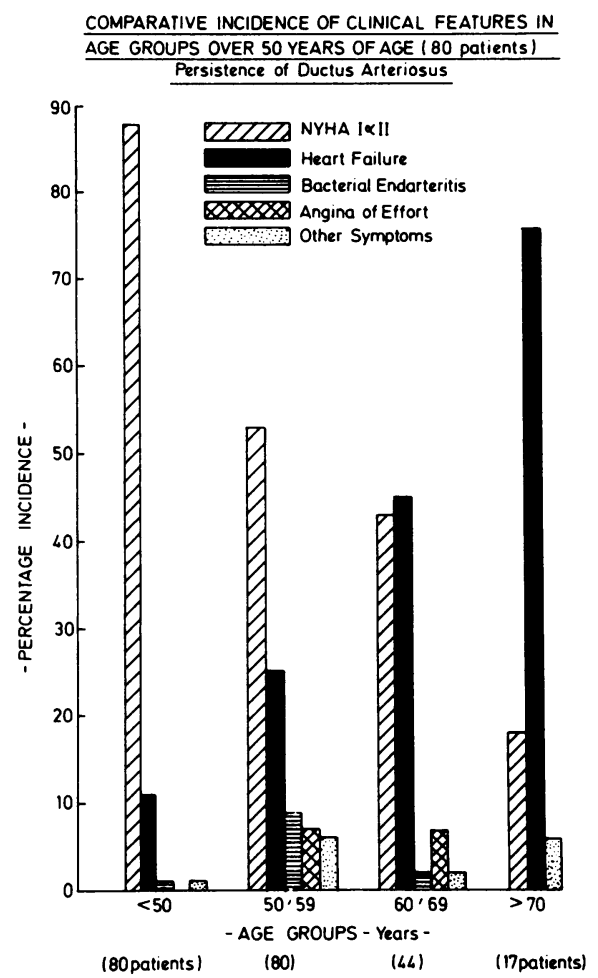

Fig. 7 Histogram combining information from 48 reports of older patients with a persistent ductus (see footnote ${ }^{\star}$ ) with the 32 Edinburgh patients. The comparative incidence of the dominant features in the different age groups of patients who have survived the first 50 years of life is shown. All patients are represented in the columns before and after their 50th birthday: 44 of them followed to over 60 years are represented a third time and the 17 who survived 70 years without surgical occlusion are also included in the last columns. Only three patients reached 80 years of age. treatment (case 5). In the other seven patients (cases 1 , $2,3,4,12,13$, and 16) surgical treatment was not advised when they were first seen because of their age and well-being. Their lack of deterioration over the years (Fig. 6) has not so far encouraged revision of the initial decision, but three of them are still under $\mathbf{6 0}$ years and the oldest is only 66 years of age.

\section{Discussion}

Older patients with a persistent ductus and a left to right shunt are probably less uncommon than is generally believed. Most patients in whom a ductus was identified in the 19th century were adults ${ }^{16}$ and in the presurgical era it was the associated disease which had sometimes led to the reporting of such older patients. ${ }^{17}$ In 1916 Manges $^{18}$ mentioned a 50 year old woman who had had eight children and he expressed the opinion that persistence of the ductus arteriosus in adults was being missed. During the past 40 years such opinions have been overshadowed by the emphasis on diagnosis and treatment in childhood in early reports of surgical experience ${ }^{19} 20$; the diagnosis of a congenital lesion may not be considered in older adults; a continuous murmur may not be present at the time of examination $^{21}$ or the murmurs may be attributed incorrectly to valve disease 111222 (cases $19,20,21$, and 32). When not suspected, a persistent ductus can readily be missed at routine necropsy. ${ }^{1323}$ In contrast, the 32 Edinburgh patients were among 165 over 18 years of age in a consecutive series of 804 patients with a persistent ductus seen over a $\mathbf{4 0}$ year period. Twelve of 80 in a necropsy series were over 50 years of age ${ }^{1}$ as were four of 59 in a regional series, ${ }^{24}$ five in a series of 43 adults, ${ }^{10}$ four of a series of 82 patients managed medically, ${ }^{25}$ and 11 of 102 adults treated surgically. ${ }^{26}$ Many other individual older patients have been reported at the time of diagnosis, of surgical treatment, or of necropsy; their ages have ranged up to 90 years but follow-up details have usually been scanty though there have been a few more detailed reports. ${ }^{6-9} 2728$

CLINICAL FEATURES OF PERSISTENT DUCTUS IN OLDER PATIENTS (Fig. 7)

Patients with a persistent ductus arteriosus and left to right shunt at over 50 years of age have been self selected by survival. Their clinical behaviour differs considerably from the well recognised patterns in childhood. In order to clarify their special characteristics, individual reports of 48 such patients, about whom sufficient detail has been published (see footnote ${ }^{\star}$, have been analysed with the 32 Edinburgh

*References to the reports of persistence of the ductus at over 50 years of age. $2,4,6-12,17,21,22,24,27,28,30,35-46,48-50,59,61,66,72,80,91$, 104 
patients. The female preponderance is greater than in younger age groups; 60 of the 80 patients were women; an overall female/male ratio of $3: 1$ which rose to $3 \cdot 2: 1$ in the 17 patients over the age of 70 years; this compares with the ratio of $2 \cdot 3$ and 2.7:1 in younger patients. ${ }^{4} 1020$ The absence of disability in earlier life is often remarkable, multiparity has been common (one woman operated upon at the age of 58 years had had 16 pregnancies with 13 living children), ${ }^{29}$ and some men have enjoyed athletic activities. ${ }^{8} 30$ This contrasts with the prolonged and severe symptoms of their contemporaries with a high pulmonary vascular resistance, severe pulmonary hypertension, and a right to left shunt through the ductus. ${ }^{431} 32$

\section{Heart failure}

Most patients follow a remarkably consistent course. Prolonged well-being in adult life is characteristic until the late onset of exertional dyspnoea. Unless treated surgically ${ }^{4}$ this soon progresses to heart failure. In contrast to an earlier opinion, ${ }^{33}$ electrocardiographic evidence of left ventricular hypertrophy becomes common in adults ${ }^{10} 34$ and is usual over the age of 60 years (Table; see Fig. 9). Isolated case reports have shown repeatedly that atrial fibrillation and gross cardiomegaly are the usual end-stage.46-10 $122227283035-45$ The age at which the end-stage has been reached has varied widely. Deterioration usually begins before the age of 60 years and a high proportion of patients operated upon at over 50 years have already had heart failure. ${ }^{26}$ Exceptional patients, however, remain free from exertional dyspnoea until the age of 70 years and beyond 689394046 (cases 5, 10, and 11).

All other modes of presentation of a persistent ductus at over the age of 50 years are uncommon.

\section{Bacterial endarteritis}

Bacterial endarteritis used to cause more than twice as many deaths as heart failure in patients of more than 3 years of age ${ }^{12}$ but is a comparatively rare complication of a persistent ductus in the older patient (Fig. 7). Though three of the 100 reports of bacterial infection collected by Cassels ${ }^{47}$ were over 50 years of age, only four other instances of endarteritis in the elderly have been traced. 244849 The oldest infected patient was 63 years of age ${ }^{50}$ and only one of the Edinburgh patients was infected (case 25).

In any survey of the persistent ductus, heart failure and bacterial endarteritis are the leading complications - the former at the extremes of life, the latter in the middle years. Heart failure is the major risk at under 2 years of age, ${ }^{51}$ is uncommon in childhood and adolescence, ${ }^{25}$ becomes more frequent as middle age is reached, ${ }^{5}$ and is the usual end-stage in older patients (Fig. 7). Heart failure was the indication for extending the initially accepted age range for surgery to the youngest and oldest patients in early surgical experience. ${ }^{52-54}$ In contrast, bacterial endarteritis is rare in infancy, uncommon the first 10 years of life,, 5 has its highest incidence in the second and third decades, 4756 and is infrequent in old age (Fig. 7). Though failure to recognise bacterial endocarditis as such remains common $^{57}$ and unfamiliarity with the infected ductus used to be widespread, ${ }^{58}$ there is no evidence that either of these factors accounts for the reduced proportion of patients in whom bacterial endarteritis is diagnosed at over 50 years of age.

\section{Exertional chest pain}

This is a relatively uncommon feature of a persistent ductus with a left to right shunt in the adult ${ }^{10} 2838$ 59-61 (cases 26, 29, and 30): It has been attributed to coronary atherosclerosis ${ }^{60}$ but this is not necessarily so; it can be relieved by division of the ductus, 1028 as it was in three Edinburgh patients, two of whom were still free from angina seven and 16 years, respectively, after operation (cases 30 and 26). In one of them preoperative coronary arteriograms had been normal (case 30). In the third, chest pain recurred 11 years after operation and increased in severity until death from myocardial infarction seven years later (case 29). In contrast, angina is common and occurs at a younger age when severe pulmonary hypertension is secondary to a high pulmonary vascular resistance. It is a common feature of the ductus with a right to left shunt. ${ }^{31} 326263$

\section{Paroxysmal arrhythmias}

Paroxysmal arrhythmias, other than atrial fibrillation, are uncommon and of uncertain prognostic significance in older patients with a persistent ductus. One of the longest survivors had had paroxysmal supraventricular tachycardia from the age of 74 years $^{6}$ and one of the otherwise symptomless Edinburgh patients was able to terminate her paroxysms of supraventricular tachycardia by Valsalva's manoeuvre (case 3). On the other hand, two severely disabled patients, one with multifocal ventricular extrasystoles, syncope, and paroxysms of undiagnosed tachycardia (case 8) and the other with paroxysms of supraventricular tachycardia, ${ }^{30}$ died suddenly at 55 and 61 years of age, respectively. They both had left ventricular hypertrophy and gross cardiomegaly. Sudden death has also been reported in younger patients with persistence of the ductus and a history of syncope. ${ }^{3}$

SYMPTOMS IN RELATION TO ANATOMICAL, CLINICAL, AND HAEMODYNAMIC FEATURES

It is not known why some patients with persistence of the ductus survive 50 years or why the prognosis varies so widely among those who do. It has been natural to assume that small size of the ductus is the determining factor. Few patients with a ductus who present clinically later than the neonatal phase of life 
have total persistence of the large fetal vessel with equality of pressures in the aorta and pulmonary artery. Partial closure is usual. It is an essential factor in the haemodynamics of those who present with a continuous murmur, and all the older patients with a left to right shunt fell into this category. Nevertheless, the anatomical size of the ductus and the volume of the left to right shunt has varied considerably in patients over 50 years of age. Size can be measured at operation or at necropsy; the size increases with growth ${ }^{64} 65$; a diameter of $8 \mathrm{~mm}$ is average in childhood but large in infancy and small in adult life; a ductus with a diameter of $10 \mathrm{~mm}$ or more must be classed as large at any age. The longest survivors without operation have had ductal lumina of only $4 \mathrm{~mm}$ and $1.5 \mathrm{~mm}$ at the ages of 85 and 90 years, respectively. 69 Most of those who have survived 60 years have had lumina or diameters of $6 \mathrm{~mm}$ or less 73639 42 (case 15), but four of the Edinburgh patients in whom the ductus was known to be small developed severe symptoms before the age of 60 years (cases 19 , 21,26 , and 39). Moreover, a few patients with a large ductus have survived to old age ${ }^{12} 2428$ (case 11). Thrombotic occlusion of a small ductus has occurred at over 50 years of age,,$^{66}$ and decrease in heart size with disappearance of a typical or decreased intensity of the continuous murmur between the ages of 61 and 71 years and at 81 years, respectively, have been reported. ${ }^{8} 9$ No other evidence of spontaneous closure has been reported in patients with a persistent ductus at over 50 years of age. None of the 22 Edinburgh patients whose physical signs had been observed for a total of 382 patient years before surgical treatment or death lost their murmurs or decreased their heart size. Though it is appreciated that neither measurements of ductal size at operation or at necropsy nor calculations deduced from ductal blood flow are always reliable, accumulated experience of all the evidence makes it improbable that late decrease in size of the ductus is common or that small size of the ductus is the sole factor in prolonged survival.

Comparatively little is known about the early physical signs in the patient with a persistent ductus who remains well until over 50 years of age. The fact that most older patients had escaped early diagnosis may suggest that the continuous murmur in childhood had been faint or absent. A more likely explanation is that auscultation had been inexperienced and that any doubts had been dismissed because of the obvious well-being of the patients. A patient of 68 years had been known to have had a continuous murmur since childhood ${ }^{45}$; the murmur was unmistakable by adult life in the five Edinburgh patients examined at under 30 years of age; persistence of a continuous murmur has also been recorded from 30 to 70 years of age. ${ }^{27}$ These observations suggest that the auscultatory features have varied little as age has increased. In contrast, there is progressive increase in heart size, ${ }^{828}$ even when the ductus is small ${ }^{7}$ (case 22) and other causes of cardiomegaly have been excluded. Eighteen of the Edinburgh patients had no cardiac enlargement when first examined, whereas only one of the six survivors without surgical treatment at over 65 years of age had a normal sized heart (case 3). Delay in increase in heart size until over 70 years 727 or even until over 80 years of age,${ }^{9}$ is rare. On the other hand, a few older patients may have developed their cardiac enlargement much earlier in life; this was noted at 19 years (case 6) and at 25 years (case 27) in two of the Edinburgh patients. Both had repeatedly declined surgical treatment and had been as active as many without cardiac enlargement.

The relative normality of pulmonary arterial pressures in the Edinburgh series (Table) can be explained in part by the sizes of the ductus and of the left to right shunt but it also shows that in these older patients the long duration of an increased pulmonary blood flow has not caused pulmonary vascular disease. ${ }^{67}$ The calculation of left to right shunts cannot be precise ${ }^{68}$ but systolic pressures of over $70 \mathrm{mmHg}$ in the pulmonary circulation of older patients have characteristically been secondary to relatively large shunts with left ventricular failure ${ }^{43469}$ (case 27). The development of left ventricular failure could also explain the rise of pulmonary arterial pressure from $37 / 15$ to $70 / 42$ $\mathrm{mmHg}$ between the ages of 60 and 68 years in the patient reported by Bell-Thomson and colleagues..$^{45}$ Indeed the absence of earlier symptoms suggests that this late sequence may be a feature of the older patient with a large ductus. At all events, no patient with a right to left shunt reaches 50 years without severe symptoms ${ }^{31} 3270-74$ and the maintenance of a relatively normal pulmonary vascular resistance is probably an important factor in the long survival of the older patient with a persistent ductus.

\section{OPERATIVE PROCEDURE}

When the diameter of the ductus is $8 \mathrm{~mm}$ or less, its surgical treatment is usually a simple, straightforward procedure. A large ductus is more readily damaged 75 and ligation is hazardous. ${ }^{76}$ An infected ductus is friable and tears readily ${ }^{50} 54$ Calcification of the ductus and of the adjoining great vessels, ${ }^{74}$ makes them brittle and liable to rupture when a clamp is applied ${ }^{77}$ (cases 21,22 , and 27). Whenever the risk of damage to the ductus is above normal it is wise to obtain proximal and distal control of the aorta before dissecting the ductus. Induced hypotension (case 28) may make the whole dissection easier and safer. In the Edinburgh series no other special techniques have been employed but a variety of methods with and without cardiopulmonary bypass have been recommended in this high risk age group.28 $44616978-84$ Transaortic ${ }^{43} 85$ and transvenous 
catheter closure 86 may prove feasible alternatives to surgical closure in some patients.

\section{POSTOPERATIVE RESULTS}

In the past, advanced age and calcification of the ductus have been regarded as contraindications to surgical treatment, ${ }^{25} 87$ but experience in Edinburgh has shown that division of the ductus in older patients has carried less risk and has afforded greater immediate benefits than might have been expected. In most patients symptoms have been relieved entirely and heart size has decreased 10122880 (Fig. 4 and 5). Atrial fibrillation may revert spontaneously to normal rhythm but reversion may not occur for a year or more (cases 30 and 31 ) or may never occur 2627 (case 21). Experience in younger patients has shown that liability to paroxysmal tachycardia may be removed by surgical treatment. ${ }^{88}$ Nevertheless, in older patients operation does not always relieve exertional dyspnoea ${ }^{26}$ or heart failure ${ }^{89}$ and may not prevent progression to death in the postoperative period ${ }^{24} 61$ (case 28 ).
INFLUENCE OF AGE ON MANAGEMENT OF PERSISTENT DUCTUS: PATHOGENESIS OF HEART FAILURE

The fundamental difference between a persistent ductus in young and in older patients is the poor correlation in the latter between eventual symptoms and heart size on the one hand, and the size of the ductus on the other. What is the evidence for an additional factor to explain the relative well-being and the prolonged survival of the older patients? Why does the age at which disability develops vary so widely and why does surgical treatment sometimes fail to arrest deterioration? Associated lesions cannot be the factor; postoperative subaortic stenosis ${ }^{90}$ is uncommon in childhood and has not been noted in adults; abnormalities of aortic and mitral valves affect younger and older patients alike ${ }^{691-94}$ (cases 19,20,21, and 22).

A large ductus often leads to heart failure in infancy. When surgical treatment is delayed into later childhood it may not relieve heart failure or prevent death. ${ }^{95}$ Experimental studies have also shown that a $35 \%$ left to

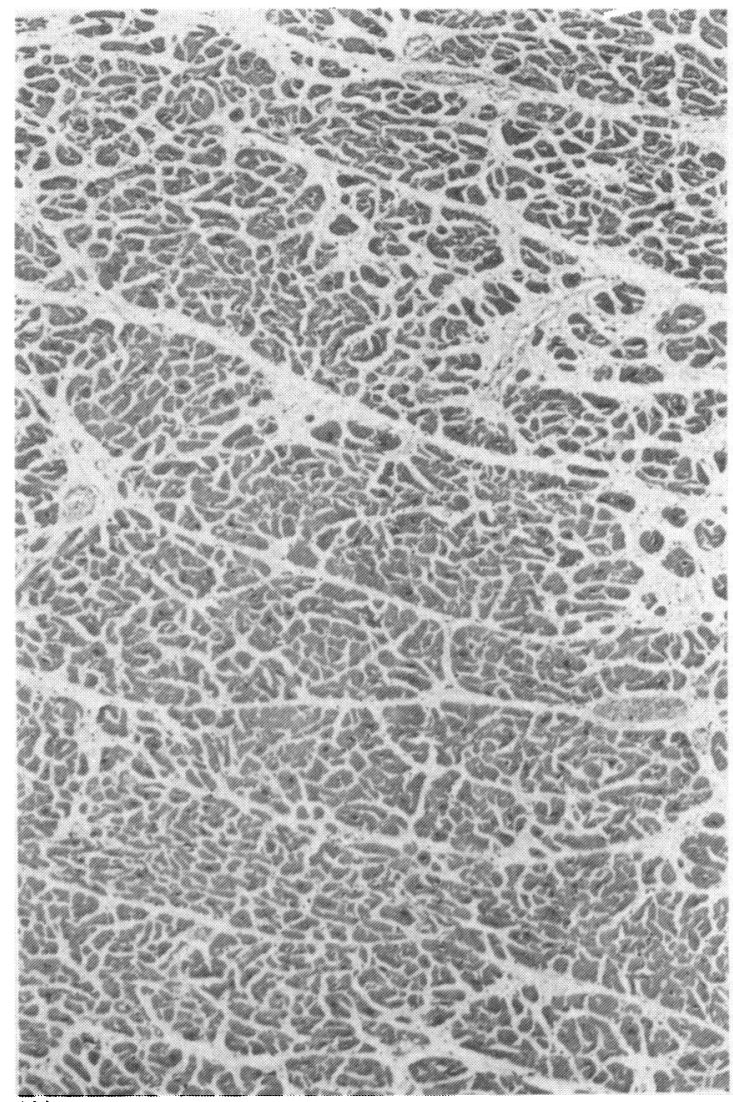

(A)

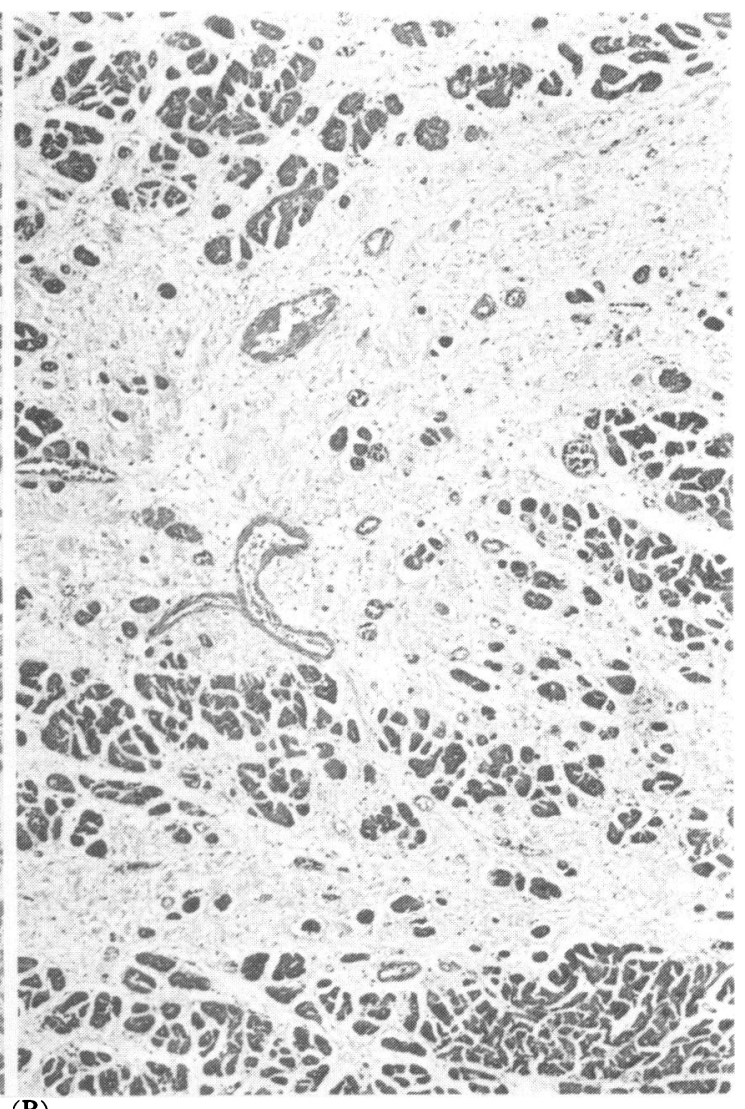

(B)

Fig. 8 Photomicrograph of the left ventricular myocardium (Haematoxylin and eosin. Original magnification $\times 50)$ case 11.(A) Normal myocardium with minimal fibrosis in the subepicardial region. (B) Considerable myocardial fibrosis in the subendocardial region. 
right shunt through a persistent ductus imposes a greater load on the left ventricle than a comparable shunt through a defect of the ventricular septum..$^{96} 97$ Left ventricular overload and irreversible dysfunction have thus been shown in large left to right shunts through the ductus. Left ventricular dysfunction has also been correlated with myocardial histology in both systolic and diastolic overloads of the left ventricle. ${ }^{98} 99$ Furthermore, left ventricular fibrosis (Fig. 8) has sometimes been obvious in the older patient, with persistence of the ductus ${ }^{7}$ (case 11) and has been noted even when the ductus has been small (case 15). It has been the only abnormality to explain death from acute left ventricular failure months or years after successful division of the ductus in older patients ${ }^{61}$ (case 28). Cassels ${ }^{100}$ has postulated that myocardial function may also be impaired by a "coronary steal" from the aortic arch as a result of a large diastolic flow through the ductus, but this can hardly be a factor when the ductus is small.

Unfortunately, the histological features of the left ventricular myocardium in persistence of the ductus have seldom been recorded; the incidence of myocardial fibrosis is thus uncertain and its aetiology is unknown. It was present to some extent in all four of the Edinburgh patients examined after death (cases 11, 15,27 , and 28); it was least in the youngest (case 27), greatest in the oldest (case 11), and was predominantly in the subendocardial region (Fig. 8). Even in the small ductus (case 15) it was readily detected and quite different from the minor increase in collagen which can be detected histologically in the subendocardial regions of the normal ageing myocardium. ${ }^{101}$ Prolonged rise in left ventricular end-diastolic pressure or increased left ventricular mass could account for its subendocardial distribution. This would accord with the increasing frequency of heart failure (Fig. 7), increasing heart size (Table), and increasing severity of electrocardiographic changes as age advances (Table; Fig. 9). As these are features of the older patient whether the ductus itself is large or small, it is possible that the abnormal histology (fibrosis) may result from a relatively small increase in left ventricular stroke volume when this has continued for over 50 years as a result of persistence of the ductus arteriosus. In effect a small shunt of long duration in some patients may be as important as a large diastolic overload for a shorter period has been shown to be in inducing left ventricular dysfunction and myocardial fibrosis. This could explain some of the anatomical and haemodynamic differences between the younger and the older patients with persistence of the ductus. It could also explain why the left ventricle, compromised by fibrosis in older patients, may not be able to respond to surgical division of the ductus which entails the loss of its outlet into the low resistance of the pulmonary circulation and the increased afterload
Persistence of Ductus Arteriosus AGE and LEFT VENTRICULAR HYPERTROPHY

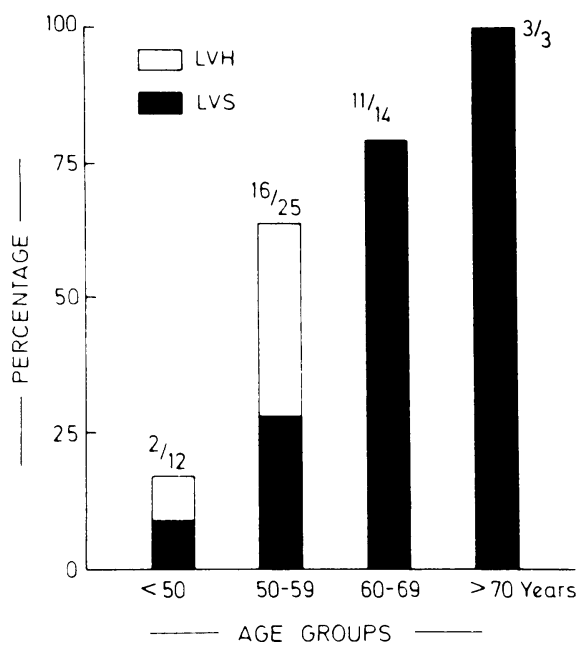

Fig. 9 Histogram showing electrocardiographic evidence of left ventricular hypertrophy $(L V H)^{15}$ in the 32 Edinburgh patients. The numbers in each age group are indicated at the head of each column; the upper figures are those with LVH. Left bundle-branch block has been grouped under LVS (left ventricular T wave Inversions).

imposed by the higher systemic vascular resistance. Postoperative atrial fibrillation (case 23), continued exertional dyspnoea, 102689 persistence of heart failure, and postoperative death ${ }^{24} 61$ (case 28), could all be explained by irreversible left ventricular dysfunction. The detection of myocardial fibrosis in the older patient with a persistent ductus is an illustration of how necropsy findings may supplement clinical investigations in clarifying the course of disease. ${ }^{102}$

Thus, though only a few older patients fail to improve after division of the ductus, the development of functional impairment of the left ventricle invalidates the proposition that the small persistent ductus need not be treated surgically at an earlier age. ${ }^{43}$ 103-105 The assertion that absence of symptoms and cardiac enlargement in older patients excludes "heart disease of any severity" $1+$ cannot be maintained and the unsupported assertion that "it is inconceivable" that the small ductus predisposes "to premature heart failure"106 can also be dismissed (Fig. 10). The heart will cease to remain small if left ventricular function deteriorates; heart failure may develop soon after the onset of symptoms and cannot always be corrected by delayed operation.

Even so, the recommendation of surgical treatment "regardless of age and lack of symptoms" 10 requires qualification when the patient is already beyond 50 years of age. The increased risks of operation ${ }^{28} 107108$ 


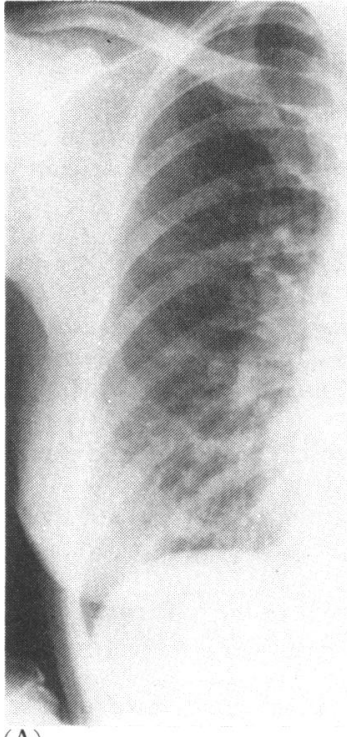

(A)

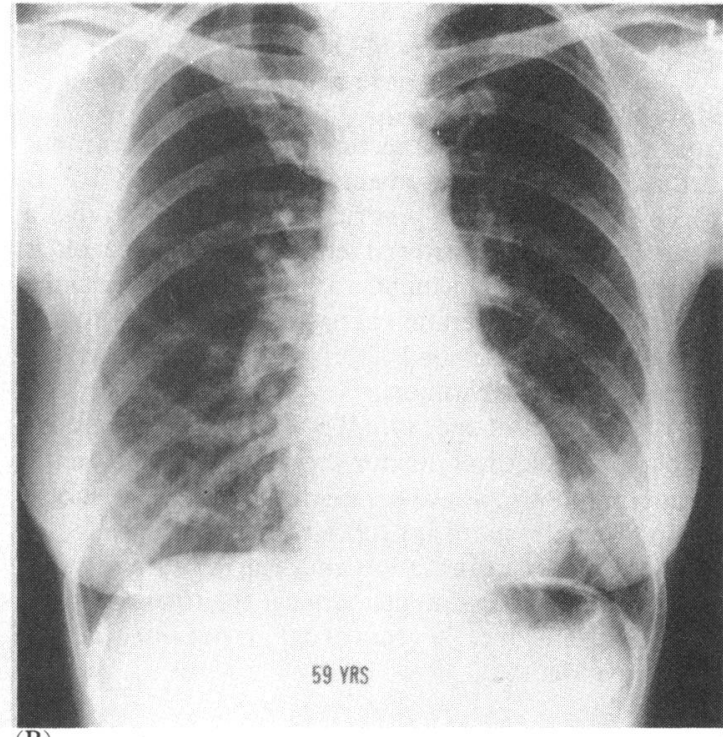

(B) have to be balanced against the fact that a normal life span is sometimes possible and may be more frequent than suggested by reported experience. Furthermore, long term control of atrial fibrillation and heart failure by medical treatment may be possible ${ }^{8}$ (cases 17 and 32 ), and safer than operation ${ }^{27}$ (case 5). The optimal time for surgical treatment is long past by 50 years of age, but once symptoms have developed both the short and long term benefits of operation far outweigh the risks. Cardiac enlargement in the absence of symptoms is also an indication for surgical treatment in most older patients; the younger the patient the stronger the indication. When an older patient has neither symptoms nor cardiomegaly the indication for operation is no longer clear; the older the patient the more likely it is that the ductus is small, ${ }^{69}$ and left ventricular function little impaired. Full investigation to confirm the diagnosis and clarify the haemodynamics may simplify subsequent management (cases 10 and 13), but the most important measure was recommended by Hubbard 38 years ago"6; it remains "watchful waiting". Increase in the heart size is often the first indication of deterioration which can then be arrested by prompt surgical treatment before the development of heart failure.

\section{Conclusions}

(1) Few patients with persistence of the ductus and a left to right shunt survive to over 50 years of age but their numbers may have been underestimated.
(2) Prolonged survival is usually, but not necessarily, associated with a small ductus. Prolonged survival is over three times more common in women. An increase in the pulmonary vascular resistance is minimal in these patients.

(3) The continuous murmur is the hallmark of the persistent ductus in the older patient, as in younger age groups. Characteristically their exercise tolerance remains normal until shortly before terminal heart failure. Atrial fibrillation, advanced left ventricular hypertrophy, and gross cardiomegaly are usual before death, whether the ductus itself is large or small.

(4) Other features of the terminal phase are uncommon: (a) bacterial endarteritis is infrequent; (b) a minority present with acute left ventricular failure, exertional chest pain, syncope, or bacterial endarteritis before the development of cardiomegaly; (c) sudden death is uncommon but does occur in patients with paroxysmal arrhythmias, cardiac enlargement, and advanced left ventricular hypertrophy.

(5) Operation is more hazardous and the outcome is less certain than in younger patients; not only because the patients are older but also because: (a) the risk of haemorrhage during dissection or clamping of calcified vessels is greater, and (b) successful division of the ductus sometimes fails to relieve symptoms and prevent death.

(6) Nevertheless, surgical treatment usually restores normal exercise tolerance and reduces heart size on a long term basis. Myocardial damage secondary to long duration of even a small left to right shunt may be the 
factor which determines the poor results in the minority of these older patients.

(7) Satisfactory results have usually been obtained by conventional division of the ductus, with suture of the great vessels but special techniques, with and without cardiac bypass, have also been developed.

(8) Impairment of left ventricular function becomes a greater risk than bacterial endarteritis in the older patient and lends weight to the opinion that the diagnosis of congenital persistence of the ductus arteriosus in childhood is itself an indication for elective surgical treatment.

(9) By 50 years of age, symptoms or cardiomegaly are almost always indications for surgical treatment. In the absence of both, however, continued medical supervision is usually more appropriate in this age group.

(10) When atrial fibrillation and heart failure respond well to medical treatment, surgical treatment, especially in patients over 70 years of age, is not essential and can be avoided.

We gratefully acknowledge the advice we have had from Dr Rae Gilchrist which one of us (RMM) has enjoyed for over 40 years. We also thank Dr David Lamb for guidance on myocardial histology.

\section{References}

1 Bullock LT, Jones JC, Dolley FS. The diagnosis and the effects of ligation of the patent ductus arteriosus. $\mathcal{F}$ Pediatr 1939; 15: 786-801.

2 Keys A, Shapiro MJ. Patency of the ductus arteriosus in adults. Am Heart f 1943; 25: 158-86.

3 Welti JJ, Körperich G. Remarques sur le prognostic de la persistance simple du canal artériel à propos de 54 cas non opérés. Arch Mal Coeur 1948; 41: 428-35.

4 Campbell M. Patent ductus arteriosus. Some notes on prognosis and on pulmonary hypertension. Br Heart $\mathcal{f}$ 1955; 17: 511-33.

5 Campbell M. Natural history of persistent ductus arteriosus. Br Heart f 1968; 30: 4-13.

6 Bain CWC. Longevity in patent ductus arteriosus. $\mathrm{Br}$ Heart f 1957; 19: 574-6.

7 Fishman L. Patent ductus arteriosus in patient surviving to 74 years. Am $\mathcal{F}$ Cardiol 1960 ; 6: 685-8.

8 White PD, Donovan H. Hearts. Their long follow-up. Philadelphia \& London: WB Saunders, 1967: 42-4.

9 White PD, Mazurkie SJ, Boschetti AE. Patency of the ductus arteriosus at 90 . N Engl F Med 1969; 280: 146-7.

10 Fairley GH, Goodwin JF. Patent ductus arteriosus in adult life. BrF Dis Chest 1959; 53: 263-77.

11 Gahagan T, Lam CR, Drake EH. Patent ductus arteriosus simulating aortic-valve regurgitation. $N$ Engl f Med 1964; 271: 463.

12 Hornsten TR, Hellerstein HK, Ankeney JL. Patent ductus arteriosus in a 72-year-old woman: successful corrective surgery. FAMA 1967; 199: 580-2.

13 Gilchrist AR. Patent ductus arteriosus and its surgical treatment. Br Heart f 1945; 7: 1-36.

14 Cassels DE. The ductus arteriosus. Springfield, Illinois:
Charles C Thomas, 1973: 331.

15 Romhilt DW, Estes EH Jr. A point-score system for the ECG diagnosis of left ventricular hypertrophy. Am Heart f 1968; 75: 752-8.

16 Marquis RM. The continuous murmur of persistence of the ductus arteriosus - an historical review. Eur Heart 7 $1980 ; 1: 465-78$.

17 Hubeny MJ. Roentgen diagnosis of patent ductus arteriosus; with report of a case complicated by presence of saccular aneurysm. $A \mathcal{F R} 1920 ; 7: 23-6$.

18 Manges $M$. Infective pulmonary endarteritis occurring with patent ductus arteriosus. With some observations on pregnancy and heart disease. New York Medical Fournal 1916; 104: 581-3.

19 Gross RE. A surgical approach for ligation of a patent ductus arteriosus $N$ Engl F Med 1939; 220: 510-4.

20 Gross RE. The patent ductus arteriosus. Observations on diagnosis and therapy in 525 surgically treated cases. Am F Med 1952; 12: 472-82.

21 Wells HG. Persistent patency of the ductus arteriosus Botalli. Transactions of the Chicago Pathological Society 1922; 11: 290-2.

22 Darier J. Persistance du canal artérial chez une femme de 51 ans. Bulletin de la Société Anatomique de Paris 1885; 60: $55-8$.

23 Wells HG. Persistent patency of the ductus arteriosus. Am F Med Sci 1908; 136: 381-400.

24 Douglas DM, Lowe KG, Brown FR, Hill IGW. Surgical treatment of patent ductus arteriosus. $\mathcal{F} R$ Coll Surg Edinb 1958; 3: 286-300.

25 Espino-Velo J, Zamora C. Patent ductus arteriosus. The natural history after the first year of life. In: Kidd BSL, Keith JD, eds. The Natural history and progress in treatment of congenital heart defects. Springfield, Illinois: Charles C Thomas, 1971: 39-50.

26 Trippestad A, Efskind L. Patent ductus arteriosus. Surgical treatment of 686 patients. Scand $\mathcal{F}$ Thorac Cardiovasc Surg 1972; 6: 38-42.

27 Storstein O, Humerfelt S, Müller O, Rasmussen $\mathrm{H}$. Patent ductus arteriosus in a woman aged 72 years. $\mathrm{Br}$ Heart $\mathcal{F} 1952$; 14: 276-8.

28 Thomas EA, Martinez HE, Wilson HE, McSwain HT. A technique for the division of difficult patent ductus arteriosus and report of its successful use in a sixty year old woman. F Cardiovasc Surg (Torino) 1965; 6: 509-15.

29 Krishnan M, Snelling MRJ. Persistent ductus arteriosus in Malaysian patients. Br Heart f 1971; 33: 699-701.

30 Calne DB, Raftery EB. Patent ductus arteriosus in an elderly man. Br Heart f 1966; 28: 716-7.

31 Whitaker W, Heath D, Brown JW. Patent ductus arteriosus with pulmonary hypertension. $\mathrm{Br}$ Heart $\mathcal{f}$ 1955; 17: 121-37.

32 Dailey FH, Genovese PD, Behnke RH. Patent ductus arteriosus with reversal of flow in adults. Ann Intern Med 1962; 56: 865-82.

33 Cosh JA. Patent ductus arteriosus. A follow-up study of 73 cases. Br Heart f 1957; 19: 13-22.

34 Ellison RC, Sloss LJ. Electrocardiographic features of congenital heart disease in the adult. Cardiovasc Clin $1979 ; 10$ (1): 119-38 (see p. 131).

35 Reid J. Four cases of aneurism of the arch of the aorta and a case of diaphragmatic hernia. Edinburgh Medical 
and Surgical fournal 1840; 53: 95-112.

36 Josefson A. Offenstehender Ductus Botalli nebst Atherom in den Ästen der Arteria pulmonalis. Nordiskt Mediciniskt Arkiv 1897; 29: 1-12.

37 Brody JG, Randell A. Patent ductus arteriosus. Case report of a woman sixty-five years, eleven and one half months of age. Ohio State Med f 1935; 31: 590-602.

38 Lindert MCF, Correll HL. Rupture of pulmonary aneurysm accompanying patent ductus arteriosus. FAMA 1950; 143: 888-91.

39 Fishman L, Silverthorne MC. Persistent patent ductus arteriosus in the aged. Am Heart $\mathcal{f}$ 1951; 41: 762-9.

40 Holman E, Gerbode R, Purdy A. The patent ductus: a review of 75 cases with surgical treatment including an aneurysm of the ductus and one of the pulmonary artery. f Thorac Surg 1953; 25: 111-42.

41 Mahaim C, Saegesser F. Quelques réflexions à propos de la ligature d'un canal artériel persistant chez une femme de 60 ans. Cardiologia 1960; 36: 65-78.

42 Aiken JE, Bifulco E, Sullivan JJ Jr. Patent ductus arteriosus in the aged. Report of this disease in a 74-yearold female. FAMA 1961; 177: 330-1.

43 Portsmann W, Hieronymi K, Wierny L, Warnke H. Nonsurgical closure of oversized patent ductus arteriosus with pulmonary hypertension: report of a case. Circulation 1974; 50: 376-81.

44 Wernly JA, Ameriso JL. Intra-aortic closure of the calcified patent ductus: a new operative method not requiring cardiopulmonary bypass. $\mathcal{f}$ Thorac Cardiovasc Surg 1980; 80: 206-10.

45 Bell-Thomson J, Jewell E, Ellis FH Jr, Schwaber JR. Surgical technique in the management of patent ductus arteriosus in the elderly patient. Ann Thorac Surg 1980; 30: 80-3.

46 Hubbard JP. The diagnosis and evaluation of compensated and uncompensated patency of the ductus arteriosus. F Pediatr 1943; 22: 50-9.

47 Cassels DE. The ductus arteriosus. Springfield, Illinois: Charles C Thomas, 1973: 230-1.

48 Terplan K. Mykotisches Aneurysma des Stammes der Pulmonalarterie mit Endarteritis des offenen Ductus Botalli mit einem Falle von Endocarditis lenta. Med Klin 1924; 20: 1331-2.

49 Hammerschlag E. Ein Fall von wahrem Aneurysma des Ductus arteriosus Botalli. Virchow's Archiv fur pathologische Anatomie und Physiologie und für Klinische Medizin 1925; 258: 1-8.

50 Touroff ASW. The results of surgical treatment of patency of the ductus arteriosus complicated by subacute bacterial endocarditis. Am Heart f 1943; 25: 187-210.

51 Keith JD, Coggin J, Parker R. Prognosis in isolated patent ductus arteriosus. In: Kidd BSL, Keith JD, eds. The natural history and progress in treatment of congenital heart defects. Springfield, Illinois: Charles C Thomas, 1971: 51-6.

52 Gross RE, Longino LA. The patent ductus arteriosus: observations from 412 surgically treated cases. Circulation 1951; 3: 125-37.

53 Krovetz LJ, Warden HE. Patent ductus arteriosus. An analysis of 515 surgically proved cases. Dis Chest 1962; 42: 46-57.

54 Jones JC. Twenty-five years' experience with the surgery of patent ductus arteriosus. 7 Thorac Cardiovasc Surg 1965; 50: 149-65.

55 Schlaepfer K. Chronic and acute arteritis of the pulmonary artery and of the patent ductus arteriosus. Arch Intern Med 1926; 37: 473-88.

56 Gelfman R, Levine SA. The incidence of acute and subacute bacterial endocarditis in congenital heart disease. Am F Med Sci 1942; 204: 324-33.

57 Cameron HM, McGoogan E. A prospective study of 1152 hospital autopsies: I Inaccuracies in death certification. II Analysis of inaccuracies in clinical diagnoses and their significance. F Pathol 1981; 133: 273-300.

58 Gilchrist AR, Mercer W. Infective endarteritis of the pulmonary artery. Lancet 1947; ii: 267-72.

59 White WH. Patent ductus arteriosus. Transactions of the Pathological Society of London 1885; 36: 182-3.

60 Kapp LA. Patent ductus arteriosus with coronary arteriosclerotic heart disease. Medical Bulletin of the Veterans Administration 1942; 19: 93-5.

61 O'Donovan TG, Beck W. Closure of the complicated patent ductus arteriosus. Ann Thorac Surg 1978; 25: 463-5.

62 Hultgren H, Selzer A, Purdy A, Holman E, Gerbode F. The syndrome of patent ductus arteriosus with pulmonary hypertension. Circulation 1953; 8: 15-35.

63 Smith G. Patent ductus arteriosus with pulmonary hypertension and reversed shunt. Br Heart $\mathcal{f}$ 1954; 16: 233-40.

64 Ekström G. The surgical treatment of patent ductus arteriosus. A clinical study of 290 cases. Acta Chir Scand 1952; suppl 169: 197.

65 Marquis RM. Persistence of the ductus arteriosus. In: Watson H, ed. Paediatric cardiology. London: LloydLuke (Medical Books), 1968: 244.

66 Jager BV. Noninfectious thrombosis of a patent ductus arteriosus. Am Heart f 1940; 20: 236-43.

67 Wood P. The Eisenmenger syndrome or pulmonary hypertension with reversed central shunt. I and II. $\mathrm{Br}$ Med f 1958; ii: 701-9 and 755-62.

68 Miller HC, Brown DJ, Miller GAH. Comparison of formulae used to estimate oxygen saturations of mixed venous blood from caval samples. Br Heart $\mathcal{F}$ 1974; 36: 446-51.

69 Robinson G, Condit D, Attai LA. Surgical treatment of difficult patent ductus arteriosus: profound hypothermia and circulatory arrest. NY State f Med 1975; 75:2190-2.

70 Luys. Persistance du canal artériel chez une femme de 52 ans. Bulletin de la Société Anatomique de Paris 1855; 30: 229-30.

71 Motzfeldt K. Drei Fälle von offenstehendem Ductus arteriosus Botalli. Dtsch Med Wochenschr 1913; 39: 2037 9.

72 Gibb WT Jr. Acute bacterial endarteritis of a patent ductus arteriosus. NY State 7 Med 1941; 41: 1861-3.

73 Espino-Vela J, Cardenas N, Cruz R. Patent ductus arteriosus; with special reference to patients with pulmonary hypertension. Circulation $1968 ; 37 / 38$, suppl V: 45-60.

74 Pochaczevsky R, Dunst ME. Coexistent pulmonary artery and aortic arch calcification. Its significance and association with patent ductus arteriosus. $A \mathcal{F} R$ 1972; 116: $141-5$. 
75 Oldham HN Jr, Collins NP, Pierce GE, Sabiston DC Jr, Blalock A. Giant patent ductus arteriosus. I Thorac Cardiovasc Surg 1064; 47: 331-6.

76 Goor DA, Lillihei CW. Patent ductus arteriosus. In: Congenital malformations of the heart: embryology, anatomy and operative considerations. New York: Grune \& Stratton, 1975: 340-51.

77 Black LL, Goldman BS. Surgical treatment of the patent ductus arteriosus in the adult. Ann Surg 1972; 175: 290 3.

78 Morrow AG, Clark WD. Closure of the calcified patent ductus. F Thorac Cardiovasc Surg 1966; 51: 534-8.

79 Arai T. Surgical treatment of patent ductus arteriosus in elderly persons with huge pulmonary artery. (Japanese) Kyobu Geka 1970; 23: 722-7.

80 Pifarré R, Rice PL, Nemickas R. Surgical treatment of calcified patent ductus arteriosus. $\mathcal{F}$ Thorac Cardiovasc Surg 1973; 65: 635-8.

81 Taira A, Akita H. Patch closure of the ductus arteriosus: an improved method. Ann Thorac Surg 1976; 21: 454-5.

82 Mok CK. A method for dividing an extremely short and large patent ductus arteriosus. $\mathcal{F} R$ Coll Surg Edinb 1978; 23: $381-2$.

83 Wright JS, Newman DC. Ligation of the patent ductus: technical considerations at different ages. $\mathcal{f}$ Thorac Cardiovasc Surg 1978; 75: 695-8.

84 Erdman S, Levinsky L, Levy MJ. A simple method for closure of patent ductus arteriosus in elderly patients. Ann Thorac Surg 1979; 27: 84-5.

85 Rashkind WJ, Cuaso CC. Transcatheter closure of patent ductus arteriosus-successful use in a 3.5 kilogram infant. Pediatr Cardiol 1979; 1: 3-7.

86 Warnecke I, Bücherl FS, Gerlach K, Kuhlmann F, Lemm W. Transvenous catheter closure of the persistent ductus arteriosus in dogs. World Congress of Paediatric Cardiology London June 1980. Poster presentation.

87 Husebye OW. Calcified ductus Botalli persistens. Acta Radiologica 1949; 32: 173-6.

88 Donzelot E, d'Allaines F, Mouquin M, Durand M, Métianu C, Vannier R. Résultats éloignés des interventions pour persistance du canal artériel. Arch Fr Pediatr 1957; 14: 939-44.

89 Ellis FH Jr, Kirklin JW, Callahan JA, Wood EH. Patent ductus arteriosus with pulmonary hypertension. $\mathcal{f}$ Thorac Surg 1956; 31: 268-85.

90 Steinherz L, Ehlers KH, Levin AR, Engle MA. Membranous subaortic stenosis and patent ductus arteriosus. Chest 1977; 72: 333-8.

91 White PD. Patent ductus arteriosus in a woman in her sixty-sixth year. FAMA 1928; 91: 1107-8.

92 Bonham-Carter RE, Walker CHM, Daley R, Matthews MB, Medd WE. Patent ductus arteriosus with an abnormal aortic valve. Br Heart f 1955; 17: 255-61.
93 Linde LM, Adams FH. Mitral insufficiency and pulmonary hypertension accompanying patent ductus arteriosus-report of three cases. Am F Cardiol 1959; 3: $740-5$.

94 Harley HRS, Watkins AG. A case of rheumatic mitral regurgitation and persistent ductus arteriosus. $\mathrm{Br}$ Heart F 1962; 24: 245-8.

95 Dry TJ, Harrington SW, Edwards JE. Irreversible cardiac disease in adult life caused by delayed surgical closure of a patent ductus arteriosus: report of a case. Proc Mayo Clin 1948; 23: 267-74.

96 Mason DT, Zelis R, Spann JF Jr, Braunwald E. Alterations of left ventricular performance and myocardial mechanics in patent ductus arteriosus and ventricular septal defect (abstract). Clin Res 1968; 16: 240.

97 Jarmakani MM, Graham TP Jr, Canent RV Jr, Spach MS, Capp MP. Effect of site of shunt on left heartvolume characteristics in children with ventricular septal defect and patent ductus arteriosus. Circulation 1969; 40: 411-8.

98 Schwarz F, Flameng W, Schaper J, et al. Myocardial structure and function in patients with aortic valve disease and their relation to postoperative results. $A m \mathcal{F}$ Cardiol 1978; 41: 661-9.

99 Schaper J, Schwarz F, Hehrlein F. Ultrastrukturelle Veränderungen im menschlichen Myokard bei Hypertrophie durch Aortenklappenfehler und deren Beziehung zur linksventrikulären Masse und Answurffraktion. Herz 1981; 6: 217-25.

100 Cassels DE. The ductus arteriosus. Springfield, Illinois: Charles C Thomas, 1973: 154.

101 Lenkiewicz JE, Davies MJ, Rosen D. Collagen in human myocardium as a function of age. Cardiovasc Res 1972; 6: 549-55.

102 Cameron HM. The autopsy as a clinical investigation. $\mathcal{f}$ $R$ Soc Med 1981; 74: 713-5.

103 Benn J. The prognosis of patent ductus arteriosus. $\mathrm{Br}$ Heart f 1947; 9: 283-91.

104 Luisada AA, Bhat P. Patent ductus in an elderly man. Chest 1974; 66: 69-70.

105 Kelly DT. Patent ductus arteriosus in adults. Cardiovasc Clin 1979; 10 (1): 321-6.

106 Anonymous. Persistent ductus arteriosus. Lancet 1968; i: $903-4$.

107 Gilchrist AR. The cardiac patient as a surgical risk. $\mathcal{f} R$ Coll Surg Edin 1961; 6: 159-78.

108 Breyer RH, Zippe C, Pharr WF, Jensik RJ, Kittle CF, Faber LP. Thoractomy in patients over age seventy years. Ten-year experience. 7 Thorac Cardiovasc Surg $1981 ; 81$ : 187-93.

Requests for reprints to Dr R M Marquis, Department of Cardiology, Royal Infirmary, Edinburgh EH3 9YW. 